\title{
PENGARUH PERSEPSI SISWA TENTANG BRAND IMAGE KAMPUS, KONDISI SOSIAL EKONOMI ORANG TUA DAN TINGKAT KEMAMPUAN AKADEMIK SISWA TERHADAP MINAT MELANJUTKAN KE PERGURUAN TINGGI
}

\author{
Yasrul Adi Firmansyah \\ e-mail:yasruladi@gmail.com \\ Rusno \\ e-mail: rusno@unikama.ac.id \\ Riril Mardiana Firdaus \\ e-mail: ririlmardiana@unikama.ac.id
}

(Program Studi Pendidikan Ekonomi, Fakultas Ekonomika dan Bisnis, Universitas Kanjuruhan, Malang)

\begin{abstract}
The purpose of the research is to reveal the influence of students' perception about the campus brand image, the socioeconomic condition of the parents and the level of academic ability on the interest of continuing to university. The research used quantitative approach with explanatory research type. The population numbered 273 students in MAN Gondanglegi. The sample of 83 students is determined using proportional random sampling. Data collection techniques used questionnaires and documentation. Based on the results of the analysis can be drawn some conclusions include: there is the influence of brand image on the interest of continuing to college, there is influence of socio-economic conditions of parents on the interest of continuing to college, there is influence of students' academic ability on the interest to continue to college, simultaneous brand image of campus, condition of socio-economic of parents and level of academic ability to interest to continue to university and value of $R 2$ equal to 0,955 which means brand image of campus, condition of socio-economic of parents and level of academic ability influence 95,5\% to interest to continue to college grade XII in MAN Gondanglegi.
\end{abstract}

Keywords : Brand Image Campus, Socioeconomic Condition of Parents, Academic Ability Level, Interest Continue to Higher Education

\begin{abstract}
Abstrak: Tujuan penelitian untuk mengungkapkan pengaruh persepsi siswa tentang brand image kampus, kondisi sosial ekonomi orang tua dan tingkat kemampuan akademik terharhadap minat melanjutkan ke perguruan tinggi. Penelitian menggunakan pendekatan kuantitatif dengan jenis penelitian explanatory research. Populasi berjumlah 273 siswa di MAN Gondanglegi. Sampel sebanyak 83 siswa ditentukan menggunakan proportional random sampling. Teknik pengumpulan data menggunakan angket dan dokumentasi. Berdasarkan hasil analisis dapat ditarik beberapa kesimpulan diantaranya : ada pengaruh brand image terhadap minat melanjutkan ke perguruan tinggi, ada pengaruh kondisi sosial ekonomi orang tua terhadap minat melanjutkan ke perguruan tinggi, ada pengaruh tingkat kemamampuan kademik siswa terhadap minat melanjutkan ke perguruan tinggi, ada pengaruh secara simultan brand image kampus, kondisi sosial ekonomi orang tua dan tingkat kemampuan akademik terhadap minat melanjutkan ke perguruan tinggi dan nilai $R 2$ sebesar 0,955 yang berarti brand image kampus, kondisi sosial ekonomi orang tua dan tingkat kemampuan akademik berpengaruh sebesar 95,5\% terhadap minat melanjutkan ke perguruan tinggi kelas XII di MAN Gondanglegi
\end{abstract}

Kata kunci : Brand Image Kampus, Kondisi Sosial Ekonomi Orang Tua, Tingkat Kemampuan Akademik, Minat Melanjutkan Ke Perguruan Tinggi 


\section{PENDAHULUAN}

Pada akhir-akhir ini arus pertumbuhan globalisasi sangat berkembang pesat dalam berbagai jenis bidang kegiatan, begitupun pada bidang pendidikan. Globalisasi sangat berbepengaruh pada bidang pendidikan, karena pendidikan merupakan upaya dalam membentuk sebuah nilai, sikap dan perilaku. Banyak sekali faktor-faktor yang dapat meningkatkan mutu dalam bidang pendidikan dan banyak sekali peneliti yang melakukan penelitian untuk meningkatkan kualitas pendidikan.

Minat melanjutkan ke perguruan tinggi disini adalah kecenderungan yang mengandung unsur perasaan senang, perhatian, keinginan, ketertarikan, kebutuhan, harapan, dorongan untuk melanjutkan ke perguruan tinggi atau jenjang yang lebih tinggi setelah lulus sekolah menengah. Dimana dengan adanya minat melanjutkan ke perguruan tinggi tersebut dapat meningkatkan kemampuan dan ilmu pengetahuan guna memper kaya pengetahuan dan dapat bermanfaat bagi orang lain. Menurut Soedomo (2008) pendidikan tinggi adalah tahap setelah pendidikan menengah yang diselenggarakan untuk menyiapkan peserta didik menjadi anggota masyarakat yang mempunyai kemampuan akademik maupun mempunyai kemampuan professional yang dapat diterapkan, pengembangan dan menciptakan IPTEK (ilmu pengetahuan dan teknologi).

Faktor yang dapat mempengaruhi minat melanjutkan ke perguruan tinggi adalah brand image kampus. Brand image kampus diartikan sebagai gambaran, kodisi, dan kesan suatu kampus di mata masyarakat. Penempatan brand image kampus di mata masyarakat harus memiliki nilai yang positif agar menjadikan daya tarik oleh para calon mahasiswa. Faktor lain yang dapat mempengaruhi minat melanjutkan ke perguruan tinggi adalah kondisi sosial ekonomi orang tua. Kondisi sosial ekonomi orang tua adalah suatu kedudukan yang diatur secara sosial dan menempatkan seseorang pada posisi tertentu dalam masyarakat, pemberian posisi itu disertai pula dengan seperangkat hak dan kewajiaban yang harus dimainkan oleh orang yang membawa status tersebut Sudarmaji (2010).

Selain faktor-faktor diatas ada juga faktor yang dapat mempengaruhi minat melanjutkan ke perguruan tinggi adalah tingkat kemampuan akademik. Kemampuan akademik merupakan kemampuan intelektual yang umumnya tercermin dalam prestasi akademik (nilai hasil belajar). Konsep kemampuan akademik adalah keyakinan individu dan evaluasi diri mengenai sifat akademis yang berhubungan dengan keterampilan dan kemampuan individu tersebut Krishnawati dan Suryani (2010).

Berdasarkan penjelasan diatas, bisa ditarik kesimpulan bahwa antara brand image kampus, kondisi sosial ekonomi orang tua, tingkat kemampuan akademik dan minat melanjutkan ke perguruan tinggi saling berkaitan dalam jenjang pendidikan perguruan tinggi. Dalam penelitian kali ini, peneliti memilih lokasi di MAN Gondanglegi alternatif pertama kerena jarak antara tempat tinggal dan sekolah dekat, kedua sekolah tersebut merupakan tempat magang peneliti sehingga memperudahkan penelitian, ketiga peneliti ingin mengetahui minat melanjutkan ke perguruan tinggi di MAN Gondanglegi yang notabennya adalah sekolah menengah atas yang berada di Kabupaten Malang.

Tujuan penelitian yang ingin dicapai dalam penelitian ini adalah (1) Untuk menganalisis pengaruh persepsi siswa tentang brand image kampus, kondisi sosial ekonomi orang tua dan tingkat kemampuan akademik siswa terhadap minat melanjutkan ke perguruan tinggi siswa kelas XII di MAN Gondanglegi. (2)Untuk menganalisis pengaruh persepsi siswa tentang brand image kampus terhadap minat melanjutkan ke perguruan tinggi siswa kelas XII di MAN Gondanglegi. (3)Untuk menganalisis pengaruh kondisi sosial ekonomi orang tua terhadap minat melanjutkan ke perguruan tinggi kelas XII di MAN Gondanglegi. (4)Untuk menganalisis pengaruh tingkat kemampuan akademik siswa terhadap minat melanjutkan ke perguruan tinggi kelas XII di MAN Gondanglegi 


\section{TINJAUAN PUSTAKA}

\section{Minat Melanjutkan Ke Perguruan Tinggi}

Minat merupakan kecenderungan dalam diri seseorang untuk tertarik pada suatu objek atau menyenangi suatu objek semakin kuat atau dekat hubungan tersebut maka semakin besar minat tersebut. Minat biasanya ditunjukan dengan pernyataan yang menunjukan lebih menyukai suatu hal dan dapat dinyatakan juga dalam partisipasi dalam ativitas yang diminatinya. Menurut Soedomo (2008:133) pendidikan tinggi merupakan kelanjutan pendidikan menengah yang diselenggarakan untuk menyiapkan peserta didik menjadi anggota masyarakat yang memiliki kemampuan akademik maupun kemampuan professional yang dapat menerapkan, pengembangan dan menciptakan ilmu pengetahuan dan teknologi.Perguruan tinggi merupakan satuan pendidikan yang menyelenggarakan pendidikan tinggi, pendidikan tinggi dapat berupa universitas, institusi, sekolah tinggi, akademi ataupun politeknik. Pada jenjang perguruan tinggi menuntut seseorang untuk lebih meningkatkan kemampuan atau ilmu pengetahuan. Yang pada dasarnya ilmu pengetahuan tersebut dapat dipergunakan setelah lulus dari perguruan tinggi, sekaligus imu tersebut dapat di salurkan kepada orang lain. Agar ilmu yang didapatkan di jenjang perguruan tinggi tersebut dapat bermanfaat bagi diri sendiri maupun orang lain.

Yang dimaksud dengan minat melanjutkan ke perguruan tinggi disini adalah kecenderungan yang mengandung unsur perasaan senang, perhatian, keinginan, ketertarikan, kebutuhan, harapan, dorongan untuk melanjutkan ke perguruan tinggi atau jenjang yang lebih tinggi setelah lulus sekolah menengah. Dimana dengan adanya minat melanjutkan ke perguruan tinggi tersebut dapat meningkatkan kemampuan dan ilmu pengetahuan guna memper kaya pengetahuan dan dapat bermanfaat bagi orang lain.

\section{Brand Image Kampus}

Brand image (Citra merek) merupakan serangkaian pemikiran/pemahaman oleh masyarakat mengenai suatu merek institusi, perusahaan, barang dagang dan sebagainya. Masyarakat akan lebih mengenal dengan brand image tersebut apabila pemilik dari brand image tersebut memberikan banyak informasi kepada masyarakat ataupun memasang iklan-iklan agar masyarakat lebih familiar.

Menurut Undang-Undang No 20 tahun 2016 pasal 1 ayat 1 merek merupakan tanda yang ditampilkan secara grafis dalam bentuk gambar, logo, warna, kata, huruf, angka, susunan warna, ke dalam bentuk dua dimensi atau tiga dimensi, suara, hologram, atau kombinasi dari dua atau lebih unsur tersebut untuk membedakan barang atau jasa yang diproduksi oleh orang atau badan hukum dalam kegiatan perdagangan barang atau jasa.

Menurut Kotler dan Armstrong (2014) menyatakan bahwa citra merek merupakan "The set of belief held about a particular brand is known as brand image". Yang artinya "Himpunan kepercayaan yang dimiliki tentang merek tertentu dikenal sebagai brand image". Menurut American Marketing Association dalam Kotler dan Keller (2011:263) Merek adalah nama, istilah, tanda, simbol, atau desain, atau kombinasi dari mereka, yang dimaksudkan untuk mengidentifikasi barang atau jasa dari satu penjual atau kelompok penjual dan untuk membedakan mereka dari para pesaing. Brand image Kampus dapat diartikan sebagai gambaran, kodisi, dan kesan suatu kampus di mata masyarakat. Penempatan brand image kampus di mata masyarakat harus memiliki nilai yang positif agar menjadikan daya tarik oleh para calon mahasiswa. 


\section{Kondisi Sosial Ekonomi Orang Tua}

Menurut Sudarmaji (2010) kondisi sosial ekonomi merupakan suatu kedudukan yang diatur secara sosial dan menempatkan seseorang pada posisi tertentu dalam masyarakat, pemberian posisi itu disertai pula dengan seperangkat hak dan kewajiaban yang harus dimainkan oleh orang yang membawa status tersebut. Sedangkan menurut W.S Winkel dalam Basrowi (2011) menyatakan bahwa pengertian kondisi sosial ekonomi memiliki makna suatu keadaan yang menunjukan pada kemampuan finansial keluarga dan perlengkapan material yang dimiliki. Faktor yang Mempengaruhi : 1) Pendidikan, 2) Pendapatan, 3) Kepemilikan Aset.

\section{Tingkat Kemampuan Akademik}

Menurut istilah kemampuan akademik terdiri dari dua kata, yaitu kemampuan dan akademik. Dalam kamus besar bahasa Indonesia kemampuan memiliki makna kecakapan, kesanggupan dan kekuatan, sedangkan pengertian akademi sendiri adalah sesuatu hal yang berkaitan dengan akademis (pendidikan). Menurut Krishnawati dan Suryani (2010) kemampuan akademik merupakan kemampuan intelektual yang umumnya tercermin dalam prestasi akademik (nilai hasil belajar). Konsep kemampuan akademik adalah keyakinan individu dan evaluasi diri mengenai sifat akademis yang berhubungan dengan keterampilan dan kemampuan individu tersebut. Kemampuan akademik siswa dapat digambarkan dari hasil dari pencapaian akademiknya. Pencapaian akademik merupakan fungsi akumulatif dari keluarga, masyarakat dan pengalaman di sekolah, baik masa lalu maupun saat ini Krishnawati dan Suryani (2010). Hal tersebut di dukung oleh pernyataan Dahar (2011) yang menyatakan bahwa pencapaian akademik siswa sebelumnya menunjukan kemapuan dan kinerja akademik siswa di kelas sebelumnya.

\section{METODE}

Jenis penelitian yang digunakan adalah explanatory research. Penelitian telah dilaksanakan di MAN Gondanglegi. Populasi berjumlah 273 siswa dan sampel penelitian 83 siswa yang ditentukan dengan teknik proportional random sampling. Variabel dalam penelitian ini terdiri dari tiga variabel bebas (independent variable). Variabel tersebut diberi simbol X1, X2 dan X3, yaitu brand image kampus, kondisi sosial ekonomi orang tua dan tingkat kemampuan akademik. Variabel terikat (dependent variable) diberi simbol Y yaitu minat melanjutkan ke perguruan tinggi. Data variabel $Y$, X1 dan X2 dikumpulkan menggunakan instrumen kuesioner (angket) sedangkan X3 menggunakan dokumentasi.

\section{HASIL DAN PEMBAHASAN}

Jika dilihat dari nilai hasil analisis uji $\mathrm{F}$ didapat statistik nilai $\mathrm{F}$ sebesar 544.888 dengan tingkat signifikan 0,000 karena tingkat signifikan lebih kecil dari 0,05, maka hasil penelitian ini menolak hipotesis penelitan Ho1 dan menerima hipotesis penelitian Ha1 yaitu ada pengaruh yang signifikan secara simultan antara brand image kampus, kondisi sosial ekonomi orang tua dan tingkat kemampuan akademik terhadap minat melanjutkan ke perguruan tinggi.

Nilai Koefisien Determinasi (R Square) menunjukkan besarnya pengaruh seluruh variabel bebas yaitu brand image kampus (X1), kondisi sosial ekonomi orang tua (X2), dan tingkat kemampuan akademik (X3) terhadap minat minat melanjutkan ke perguruan tinggi (Y), jadi ( $\mathrm{R}$ 
Square) 0,955 memiliki makna brand image kampus, kondisi sosial ekonomi orang tua dan tingkat kemampuan akademik mampu memberikan kontribusi sebesar 95,5\% terhadap perubahan minat melanjutkan ke perguruan tinggi (Y) dengan demikian sisanya 4,5\% dipengaruhi oleh variabel lain yang tidak termasuk dalam penelitian ini. misalnya : biaya pendidikan, pengaruh motivasi, pengaruh teman sebaya dan lain-lain.

Untuk mengetahui pengujian hipotesis pertama, maka menggunakan uji $\mathrm{F}$ dan untuk menguji hipotesis ke dua, tiga, dan empat menggunakan uji t.

Pengaruh brand image kampus, kondisi sosial ekonomi orang tua, dan tingkat kemampuan akademik terhadap minat melanjutkan ke perguruan tinggi

Hasil statistik menunjukkan bahwa ada pengaruh yang signifikan brand image kampsu, kondisi sosial ekonomi orag tua dan tingkat kemampuan akademik terhadap minat melanjutkan ke perguruan tinggi. Hal ini dibuktikan dari hasil analisis uji F didapat statistik nilai F sebesar 544.888 dengan tingkat signifikan 0,000 karena tingkat signifikan lebih kecil dari 0,05, maka hasil penelitian ini menolak hipotesis penelitian Ho1 dan menerima hipotesis penelitian $\mathrm{H} 1$ yaitu: ada pengaruh yang signifikan secara simultan antara brand image kampus, kondisi sosial ekonomi orang tua dan tingkat kemampuan akademik terhadap minat melanjutkan ke perguruan tinggi.

\section{Pengaruh brand image kampus terhadap minat melanjutkan ke perguruan tinggi}

Hasil analisis statistik menunjukkan bahwa ada pengaruh yang signifikan antara brand image terhadap minat melanjutkan ke perguruan tinggi. Hal ini dibuktikan dari hasil analisis uji $\mathrm{t}$ untuk variabel X1 (brand image kampus) sebesar 5,794 dengan tingkat signifikan sebesar 0,000. Karena tingkat signifikannya lebih kecil dari 0,05, maka variabel X1 (brand image kampus) berpengaruh terhadap variabel Y (minat melanjutkan ke perguruan tinggi). Sehingga H2 diterima dan Ho2 ditolak.

Pengaruh kondisi sosial ekonomi orang tua terhadap minat melanjutkan ke perguruan tinggi

Hasil analisis statistik menunjukkan bahwa ada pengaruh yang signifikan antara kondisi sosial ekonomi orang tua terhadap minat melanjutkan ke perguruan tinggi. Hal ini dibuktikan dari hasil analisis uji t untuk variabel X2 (kondisi sosial ekonomi orang tua) sebesar 16.953 dengan tingkat signifikan sebesar 0,000. Karena tingkat signifikannya lebih kecil dari 0,05, maka variabel X2 (kondisi sosial ekonomi orang tua) berpengaruh terhadap variabel Y (minat melanjutkan ke perguruan tinggi). Sehingga H3 diterima dan Ho3 ditolak.

\section{Pengaruh tingkat kemampuan akademik terhadap minat melanjutkan ke perguruan tinggi}

Hasil analisis statistik menunjukkan bahwa ada pengaruh yang signifikan antara tingkat keampuan akademik terhadap minat melanjutkan ke perguruan tinggi. Hal ini dibuktikan dari hasil analisis uji t untuk variabel X3 (tingkat keampuan akademik) sebesar -2.802 dengan tingkat signifikan sebesar 0,006. Karena tingkat signifikannya lebih kecil dari 0,05, maka variabel X3 (tingkat keampuan akademik) berpengaruh terhadap variabel Y (minat melanjutkan ke perguruan tinggi). Sehingga H4 diterima dan Ho4 ditolak.

\section{KESIMPULAN}

Berdasarkan hasil analisis yang telah dikemukakan pada bab sebelumnya, maka dapat ditarik beberapa kesimpulkan bahwa ada pengaruh positif dan signifikan brand image kampus, kondisi sosial ekonomi orang tua dan tingkat kemampuan akademik terhadap minat melanjutkan ke perguruan tinggi. Berdasarkan hasil penelitian ini, maka saran yang diajukan adalah (1) Hasil 
penelitian ini menunjukan bahwa brand image kampus yang memiliki kualitas baik dapat digunakan oleh perguruan tinggi untuk pedoman dalam menarik minat calon mahasiswa untuk melanjutkan ke perguruan tinggi yang bersangkutan. Dengan demikian perguruan tinggi harus memiliki brand image kampus yang baik untuk mendapatkan mahasiswa baru. (2) Agar siswa mengetahui seberapa besar pengaruh kondisi sosial ekonomi orang tua terhadap minat melanjutkan ke perguruan tinggi sehingga dapat digunakan siswa sebagai dasar dalam pengambilan keputusan (3) Sebagai usaha bagi sekolah atau guru untuk dapat meningkatkan tingkat kemampuan akademik siswa agar siswa lebih memiliki sumber daya manusia yang berkualitas. (4) Bagi peneliti selanjutnya, penelitian ini masih dapat dikembangkan lagi melalui variabel yang belum diteliti oleh penelitian ini. Variabel yang dapat digunakan untuk mempengaruhi minat melanjutkan ke perguruan tinggi adalah biaya pendidikan, pengaruh motivasi dan pengaruh teman sebaya.

\section{DAFTAR PUSTAKA}

Basrowi. 2011. Kewirausahaan untuk Perguruan Tinggi. Bogor: Ghalia Indonesia.

Dahar, Ratna Wilis. 2011. Teori-Teori Belajar . Jakarta : Erlangga.

Krishnawati, N., Suryani. 2010. Bahan Dasar untuk Pelayanan Konseling pada Satuan Pendidikan Menengah. Grasindo.

Sudarmadji, Slamet et al. 2010. Analisa Bahan Makanan dan Pertanian. Yogyakarta: Penerbit Liberty Yogyakarta dengan Pusat antar Universitas Pangan dan Gizi Universitas Gadjah Mada.

Soedomo, Hadi. 2008. Pendidikan (Suatu Pengantar). Surakarta: Lembaga Pengembangan Pendidikan (LPP) UNS dan UPT Penerbitan dan Percetakan UNS (UNS Press).

Kotler \& gary Armstrong. 2014. Principle of marketing. New jersey : pearson prentice hall.

Kotler, Philip and Kevin Lane Keller, 2011. Manajemen Pemasaran, Edisi 13 Jilid 1 dan 2, Alih Bahasa : Bob Sabran.Jakarta: Erlangga. 